\title{
Spatial Analysis of Seismic Hazard based on Dynamical Characteristics of Soil in Kota Baru, South Lampung
}

\author{
V L Ipmawan ${ }^{1, \mathrm{a}}$, I N P Permanasari ${ }^{1}$, and R N Siregar ${ }^{1}$ \\ ${ }^{1}$ Physics of Earth Division, Departement of Physics, \\ Institut Teknologi Sumatera, Indonesia \\ acorresponding author email: vico.luthfi@fi.itera.ac.id
}

\begin{abstract}
Kota Baru, a new capital Lampung province location, planned and developed since 2012, will be a densely populated in near time. The province located in near Semangko fault, southern of Sumatra Island, is a vulnerable area to earthquake. Seismometer was deployed for 15 points in Kota Baru for recording mictrotremor. The signal was analyzed by HVSR method produced fundamental frequency $f_{0}$, amplitude $A_{0}$, and seismic vulnerability index $K g$. The range of frequency value is about $0.56 \mathrm{~Hz}$ to $1.46 \mathrm{~Hz}$. The range of amplitude value is about 2.3 to 6.17 . There is linear relation between $K g$ and the damage caused by earthquake. The Kota Baru classification of seismic hazard map was generated by plotting the value of $K g$. The area at the northeast of Kota Baru is more risky to be inhabited because it has higher value of $K_{g}$. The more safety area located in near T7 and T15 because it has lower value of $K_{g}$ than the others.
\end{abstract}

\section{Introduction}

Kota Baru located in South Lampung regency is an area planed to be the new capital of Lampung province. This situation will make Kota Baru to be populous city in near time. Lampung province located in the southern of Sumatra island is vulnerable to earthquake because of it location near Semangko fault. Interaction of Indian-Australian, Eurasian, and Pacific plate is very potential to make other faults that can be a new source of earthquake.

Earthquake prediction is still too difficult because the earth interior is very complex. Another mitigation method for reducing the earthquake loss is seismic hazard mapping from the parameter of soil characteristics, like dominant frequency $f_{o}$, amplification factor $A_{o}$, and seismic vulnerability index $K g$. All of these parameters can be obtained by Horizontal Vertical Spectral Ratio method introduced by Nakamura that widely used for site effect studies by means of analyzing of microtremor recordings.

The research site is located in Kota Baru, South Lampung Regency $\left(5,28064^{\circ}\right.$ to $5,29936^{\circ} \mathrm{S}$, and $105,3740^{\circ}$ to $105,4289^{\circ} \mathrm{E}$ ). The site is at distance, approximately, $23 \mathrm{~km}$ from Bandar Lampung Town. Based on Tanjung Karang geological map, All of Kota Baru area is a part of Barisan zone volcanic sedimentary. The rocks unit are dominated by pumiceous tuff, rhyolitic tuff, welded tuff tuffit, tuffaceous claystone, and tuffaceous standstones.

\section{Microtremor}


Every time, the surface of Earth is always in motion at seismic frequencies. These constant ambient vibrations of the Earth's surface are called microseisms or microtremors. The classification of these ambient vibrations [1] can be seen in Table 1. The amplitude of these microtremors is, with some extreme exceptions, generally very small. Displacements are in the order of 10-4 to $10-2 \mathrm{~mm}$. Accordingly, microtremor activity varies over time. This variation is very complex and irregular, and not repeatable [2].

Table 1. Ambient vibration classification based on it source

\begin{tabular}{lll}
\hline & Nature & Living thing \\
\hline Name & Microseismic & microtremor \\
Frequency & $0.1-0.5$ to $1 \mathrm{~Hz}$ & 0.5 to $1-10 \mathrm{~Hz}$ \\
& & traffic, industry, human \\
Source & ocean wave & activity \\
Arrival wave & Surface wave & surface wave and body wave \\
Amplitude variability & related to storm or ocean wave & day/night, weekend
\end{tabular}

\section{Horizontal to Vertical Spectral Ratio (HVSR)}

HVSR method [2] based on spectral analysis of microtremor data for estimating frequency at the specific area. The fundamental routine of HVSR method is the horizontal spectrum divided by the vertical spectrum. HVSR method can figure out local sites effect and produce dominant frequency and amplification factor. Flow chart about HVSR method can be seen in Figure 1. 


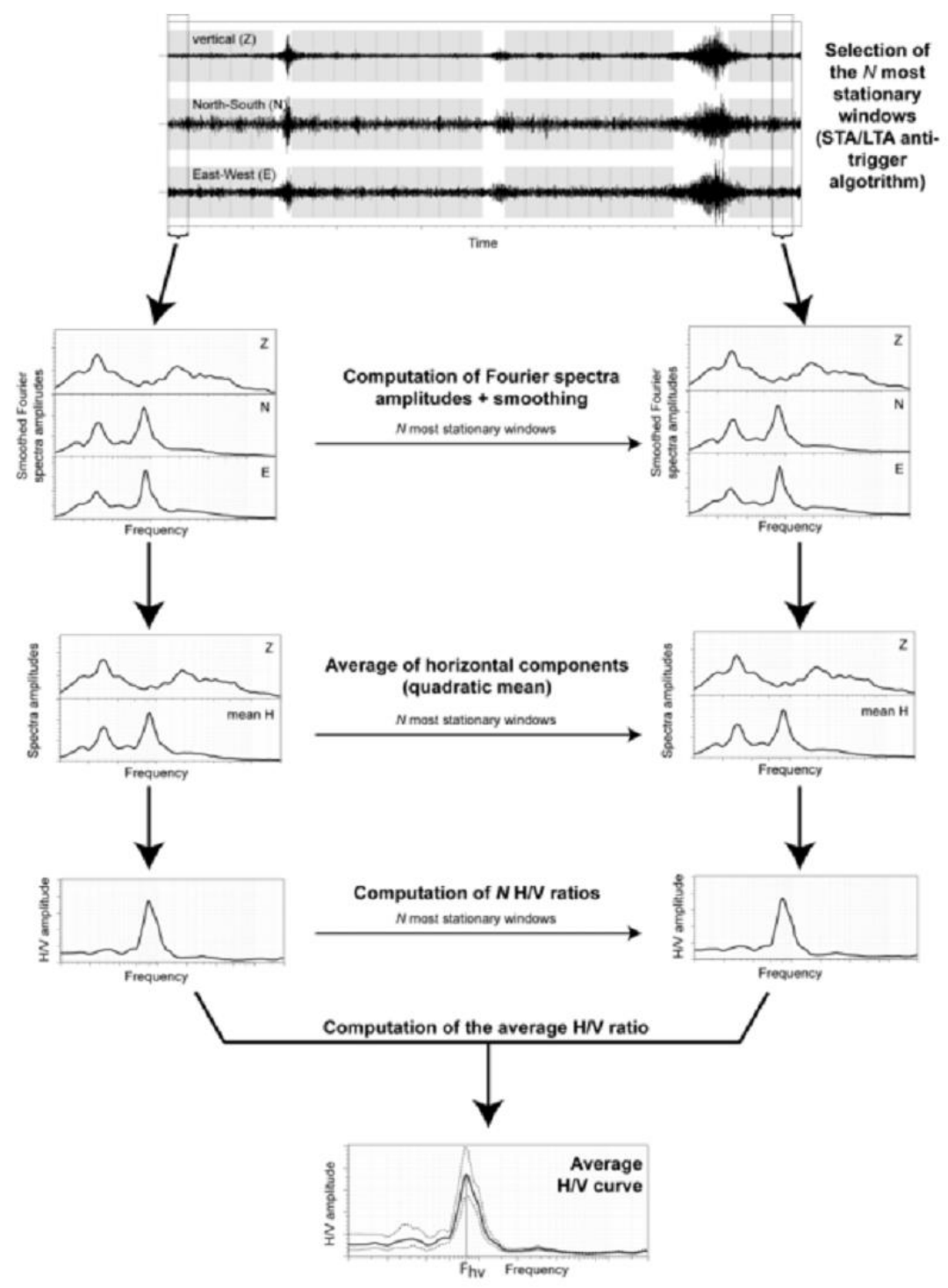

Figure 1. HVSR flow chart [1]

\subsection{Dominant frequency (fo)}

Dominant frequency can be obtained simultaneously when $\mathrm{H} / \mathrm{V}$ graphic is produced by HVSR method. Dominant frequency is the peak of $\mathrm{H} / \mathrm{V}$ curve. It means that the frequency is a fundamental natural frequency of deposits. The reliability of its value will increase with the sharpness of the H/V peak. The first requirement, before extraction of information and any interpretation, concerns the reliability of the $\mathrm{H} / \mathrm{V}$ curve. Reliability implies stability. Three criteria for a reliable $\mathrm{H} / \mathrm{V}$ curve are based on the relation of peak frequency to the window length, number of significant cycles, and standard deviation of peak amplitude. Six criteria for a clear peak are based on the realtion of the peak amplitude to the level of the HVSR curve elsewhere, and standard deviations of the peak frequency and of its amplitude (the amplitude should decrease rapidly on each side) if alla three criteria for reliable curve and at least five criteria for clear peak are fulfilled, the frequency of the peak is considered to be the fundamental frequency of sediments. All of criteria can be seen in Figure 2 . 


\begin{tabular}{|l|l|}
\hline Criteria for a reliable $H / V$ curve \\
i) & $\mathrm{f}_{0}>10 / \mathrm{I}_{\mathrm{w}}$ \\
& and \\
ii) & $\mathrm{n}_{\mathrm{C}}\left(\mathrm{f}_{0}\right)>200$ \\
and & \\
iii) $\sigma_{\mathrm{A}}(\mathrm{f})<2$ for $0.5 \mathrm{f}_{0}<\mathrm{f}<2 \mathrm{f}_{0}$ if $\mathrm{f} 0>0.5 \mathrm{~Hz}$ \\
or $\sigma_{\mathrm{A}}(\mathrm{f})<3$ for $0.5 \mathrm{f}_{0}<\mathrm{f}<2 \mathrm{f}_{0}$ if $\mathrm{f} 0<0.5 \mathrm{~Hz}$
\end{tabular}

Criteria for a clear $\mathrm{H} / \mathrm{V}$ peak (at least 5 out of 6 criteria fulfilled)

i) $\exists f^{-} \in\left[f_{0} / 4, f_{0}\right] \mid A_{H / v}\left(f^{-}\right)<A_{0} / 2$

ii) $\exists f^{+} \in\left[f_{0}, 4 f_{0}\right] \mid A_{H / V}\left(f^{+}\right)<A_{0} / 2$

iii) $A_{0}>2$

iv) $f_{\text {peak }}\left[A_{H / v}(f) \pm \sigma_{A}(f)\right]=f_{0} \pm 5 \%$

v) $\sigma_{f}<\varepsilon\left(f_{0}\right)$

vi) $\sigma_{A}\left(f_{0}\right)<\theta\left(f_{0}\right)$
- $I_{w}=$ window length

- $\mathrm{n}_{\mathrm{w}}=$ number of windows selected for the average H/V curve

- $\mathrm{n}_{\mathrm{c}}=\mathrm{I}_{\mathrm{w}} \cdot \mathrm{n}_{\mathrm{w}} \cdot \mathrm{f}_{0}=$ number of significant cycles

- $f$ = current frequency

- $f_{\text {sensor }}=$ sensor cut-off frequency

- $f_{0}=H / V$ peak frequency

- $\sigma_{f}=$ standard deviation of H/V peak frequency $\left(f_{0} \pm \sigma_{f}\right)$

- $\varepsilon\left(f_{0}\right)=$ threshold value for the stability condition $\sigma_{f}<\varepsilon\left(f_{0}\right)$

- $A_{0}=H / V$ peak amplitude at frequency $f_{0}$

- $A_{H / V}(f)=H / V$ curve amplitude at frequency $f$

- $f=$ frequency between $f_{0} / 4$ and $f_{0}$ for which $A_{H / V}(f)<A_{0} / 2$

- $f^{+}=$frequency between $f_{0}$ and $4 f_{0}$ for which $A_{H / N}\left(f^{+}\right)<A_{0} / 2$

- $\sigma_{\mathrm{A}}(\mathrm{f})=$ "standard deviation" of $A_{H / V}(f), \sigma_{A}(f)$ is the factor by which the mean $A_{H / V}(f)$ curve should be multiplied or divided

- $\sigma_{\log H / V}(f)=$ standard deviation of the $\log A_{H / V}(f)$ curve, $\sigma_{\log H / V}(f)$

is an absolute value which should be added to or subtracted from the mean $\log A_{H N}(f)$ curve

- $\theta\left(f_{0}\right)=$ threshold value for the stability condition $\sigma_{A}(f)<\theta\left(f_{0}\right)$

- $\mathrm{V}_{\mathrm{s}, \mathrm{av}}=$ average $\mathrm{S}$-wave velocity of the total deposits

- $\mathrm{V}_{\mathrm{s}, \mathrm{surf}}=\mathrm{S}$-wave velocity of the surface layer

- $\mathrm{h}=$ depth to bedrock

- $\mathrm{h}_{\min }=$ lower-bound estimate of $\mathrm{h}$

\begin{tabular}{|c|c|c|c|c|c|}
\hline \multicolumn{7}{|c|}{ Threshold Values for $\sigma_{\mathrm{f}}$ and $\sigma_{\mathrm{A}}\left(\mathrm{f}_{\mathrm{O}}\right)$} \\
\hline Frequency range $[\mathrm{Hz}]$ & $<0.2$ & $0.2-0.5$ & $0.5-1.0$ & $1.0-2.0$ & $>2.0$ \\
\hline$\varepsilon\left(\mathrm{f}_{0}\right)[\mathrm{Hz}]$ & $0.25 \mathrm{f}_{0}$ & $0.20 \mathrm{f}_{0}$ & $0.15 \mathrm{f}_{0}$ & $0.10 \mathrm{f}_{0}$ & $0.05 \mathrm{f}_{0}$ \\
\hline$\theta\left(\mathrm{f}_{0}\right)$ for $\sigma_{\mathrm{A}}\left(\mathrm{f}_{0}\right)$ & 3.0 & 2.5 & 2.0 & 1.78 & 1.58 \\
\hline $\log \theta\left(\mathrm{f}_{0}\right)$ for $\sigma_{\log H \mathrm{~N}}\left(\mathrm{f}_{0}\right)$ & 0.48 & 0.40 & 0.30 & 0.25 & 0.20 \\
\hline
\end{tabular}

Figure 2. Criteria for Reliability of HVSR curve [1]

\subsection{Amplification (A0)}

Amplification can be obtained from H/V curve peak produced by HVSR method. Amplification is influenced by S-wave velocity $v_{s}$, density $\rho$, P-wave velocity $v_{p}$, and shear-wave attenuation $Q_{s}$ [4]. The reliability of $f_{0}$ will increase with the sharpness of the $\mathrm{H} / \mathrm{V}$ peak $A_{0}$. This value may however be considered as indicative of the impedance contrasts at the site under study [1].

\subsection{Seismic vulnerability index $(\mathrm{Kg})$}

Seismic vulnerability index is a parameter related with the vulnerability level of area from earthquake risk. There is linear relation between $K_{g}$ and the damage caused by earthquake. The damage caused by earthquake is bigger when the value of $K_{g}$ at the area is higher. The index can be obtained by:

$$
K_{g}=\frac{A_{0}^{2}}{f_{0}}
$$

$A_{0}$ is amplification and $f_{0}$ is dominant frequency.

\section{Kota Baru classification of seismic hazard map}

The seismometer was deployed at 15 locations in Kota Baru for obtaining microtremor recordings. Distribution of location can be seen in Figure 3. Microtremor data were analyzed by HVSR method. The most stationary recording was chosen manually for the further analysis. Some parameters were inputted in smoothing parameter based on the condition of the curve. The majority value was 10 for Konno \& Ohmachi smoothing parameter. For improving the clarity and stability, the smaller value 
was inputted. All of $\mathrm{H} / \mathrm{V}$ peak from 15 locations were reliable peak. From these reliable peak, $f_{0}$ and $A_{0}$ can be obtained, vice versa the $K_{g}$. All of these values can be seen in Table 2 .

Tabel 2. Some soil parameters value obtained by HVSR method

\begin{tabular}{llllll}
\hline Locations & Longitude (E) & Latitude $(\mathbf{S})$ & $\boldsymbol{f}_{\boldsymbol{o}}$ & $\mathbf{A}_{\mathbf{0}}$ & $\mathbf{K}_{\mathbf{g}}$ \\
\hline T10 & 105,4188 & $-5,28139$ & 0,59 & 4,4 & 32,8 \\
T15 & 105,4189 & $-5,29394$ & 1,44 & 3,25 & 7,3 \\
T4 & 105,3931 & $-5,28494$ & 0,63 & 5,34 & 45,3 \\
T5 & 105,391 & $-5,29336$ & 0,66 & 3,81 & 22,0 \\
T6 & 105,3909 & $-5,28442$ & 0,78 & 3,55 & 16,2 \\
T1 & 105,3784 & $-5,28064$ & 0,56 & 3,47 & 21,5 \\
T2 & 105,3788 & $-5,28689$ & 0,59 & 3,22 & 17,6 \\
T3 & 105,374 & $-5,29908$ & 0,63 & 5,34 & 45,3 \\
T9 & 105,4062 & $-5,29828$ & 1,19 & 5,84 & 28,7 \\
T8 & 105,4053 & $-5,288$ & 0,8 & 4,14 & 21,4 \\
T7 & 105,4047 & $-5,28208$ & 0,75 & 2,3 & 7,1 \\
T11 & 105,4154 & $-5,28889$ & 1,46 & 6,17 & 26,1 \\
T12 & 105,4179 & $-5,29936$ & 1,17 & 5,58 & 26,6 \\
T14 & 105,428 & $-5,28783$ & 0,67 & 4,25 & 27,0 \\
T13 & 105,4289 & $-5,28122$ & 0,7 & 4,64 & 30,8 \\
\hline
\end{tabular}

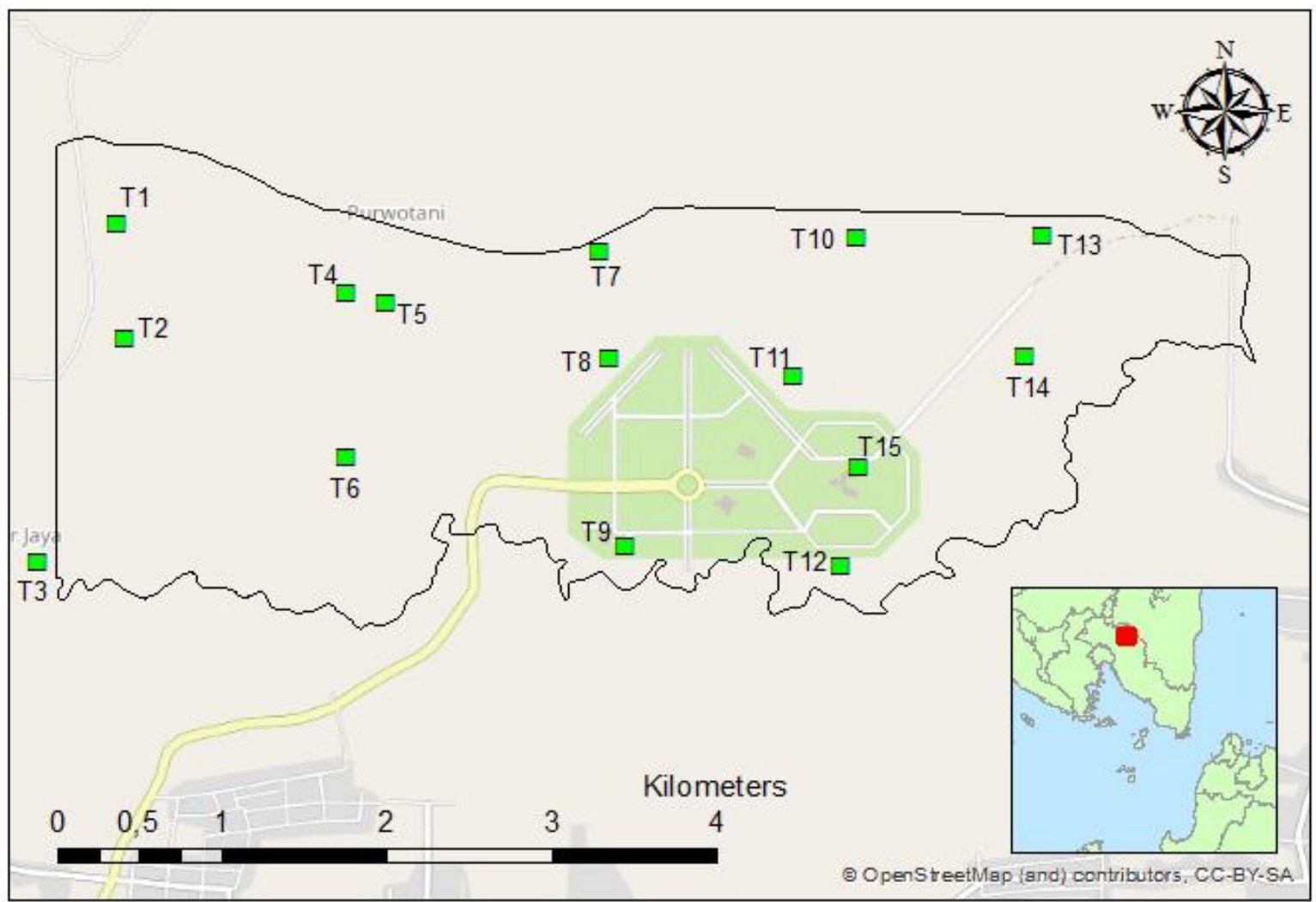

Figure 3. Distribution of recording locations denoted by green solid squares 
The range of frequency value obtained by HVSR method was $0.56 \mathrm{~Hz}$ to $1.46 \mathrm{~Hz}$. These value is suitable with the range of microtremor in Table 1 . All of spectrums at 15 recording locations can be seen in Figure 4. Spectrums of locations T1, T2, T4, T5, T6, T7, T8, T14, and T15 exhibit two peaks spectrum with $f_{0}>f_{1}$. We suggest that these locations have two large contrasts at shallow and large depth at two different scales.

The range of amplitude value obtained by HVSR method was 2.3 to 6.17. From both value, $f_{0}$ and $A_{0}$, $K_{g}$ can be obtained. The Kota Baru classification of seismic hazard map can be generated by plotting the value of $K_{g}$ at the longitude and latitude of locations. The map can be seen in Figure 5. Area at the northeast of Kota Baru is more risky to be inhabited because it has higher value of $K_{g}$. The more safety area located in near T7 and T15 because it has lower value of $K_{g}$ than the others.
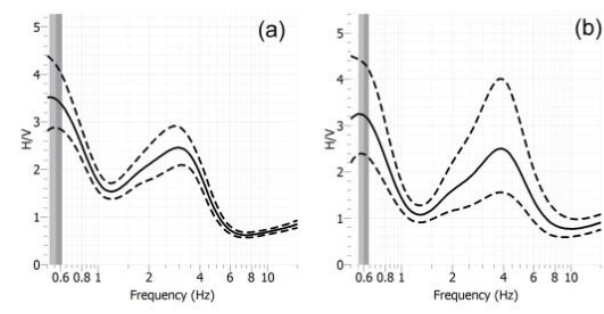

(b)

(h)
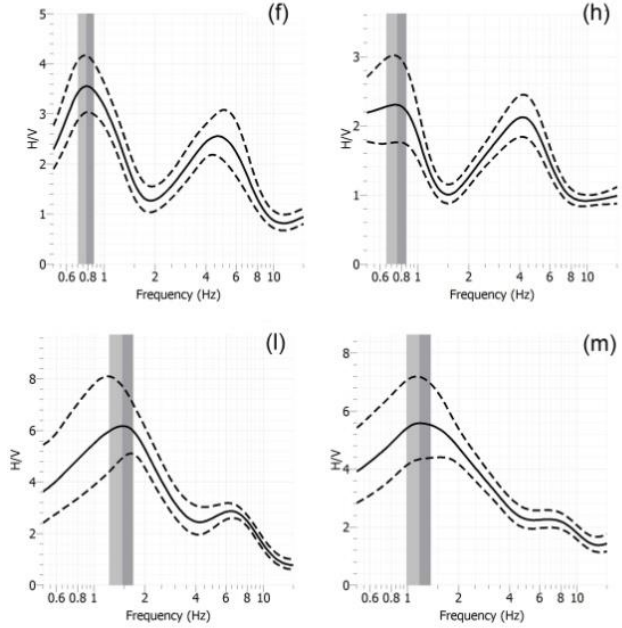

(l)

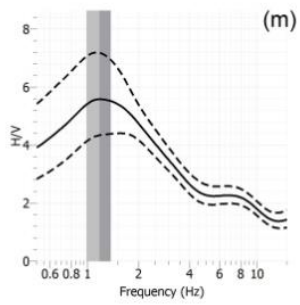

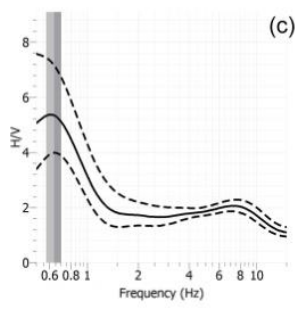
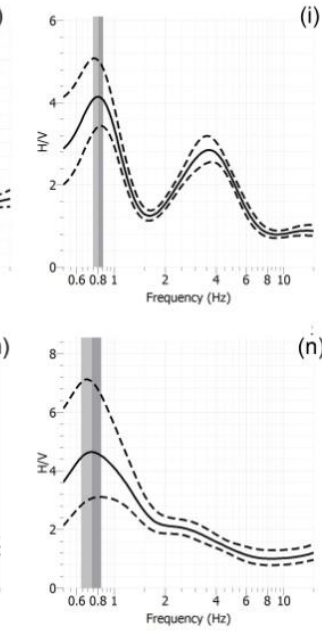

c)
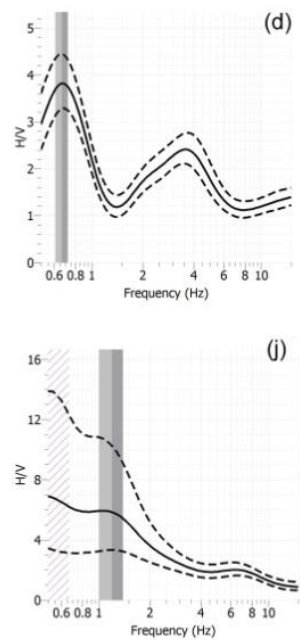

d)

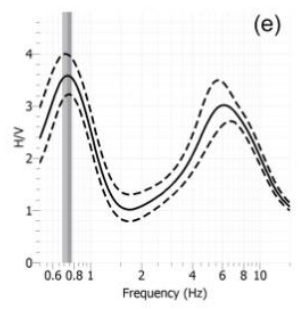

(j)
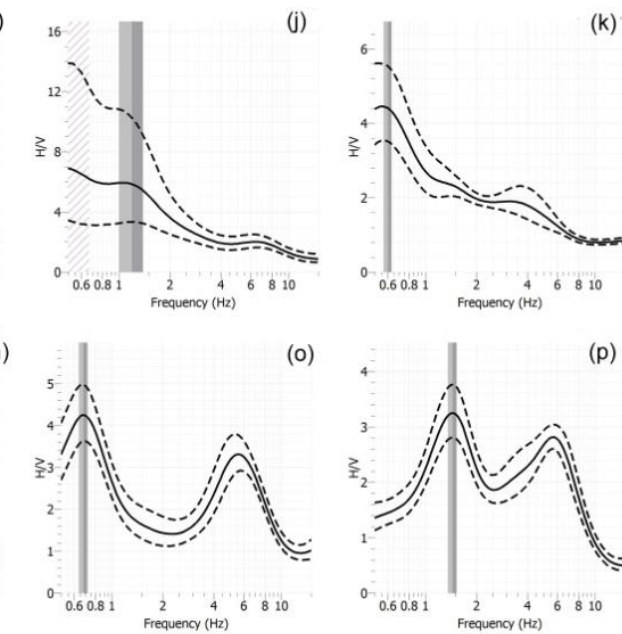

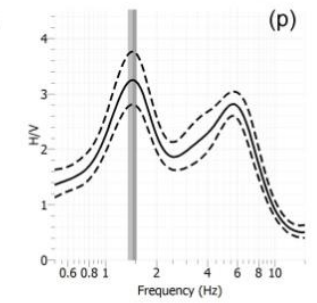

Figure 4. Spectrums of 15 locations, a) spectrums of $\mathrm{T} 1, \mathrm{~b}$ ) spectrums of $\mathrm{T} 2$, c) spectrums of $\mathrm{T} 3, \mathrm{~d}$ ) spectrums of T4, e) spectrums of T5, f) spectrums of T6, g) spectrums of T7, h) spectrums of T8, i) spectrums of $\mathrm{T} 9, \mathrm{j}$ ) spectrums of $\mathrm{T} 10, \mathrm{k}$ ) spectrums of $\mathrm{T} 11, \mathrm{l}$ ) spectrums of $\mathrm{T} 12, \mathrm{~m}$ ) spectrums of $\mathrm{T} 13$, n) spectrums of $\mathrm{T} 14, \mathrm{o}$ ) spectrums of $\mathrm{T} 15$ 


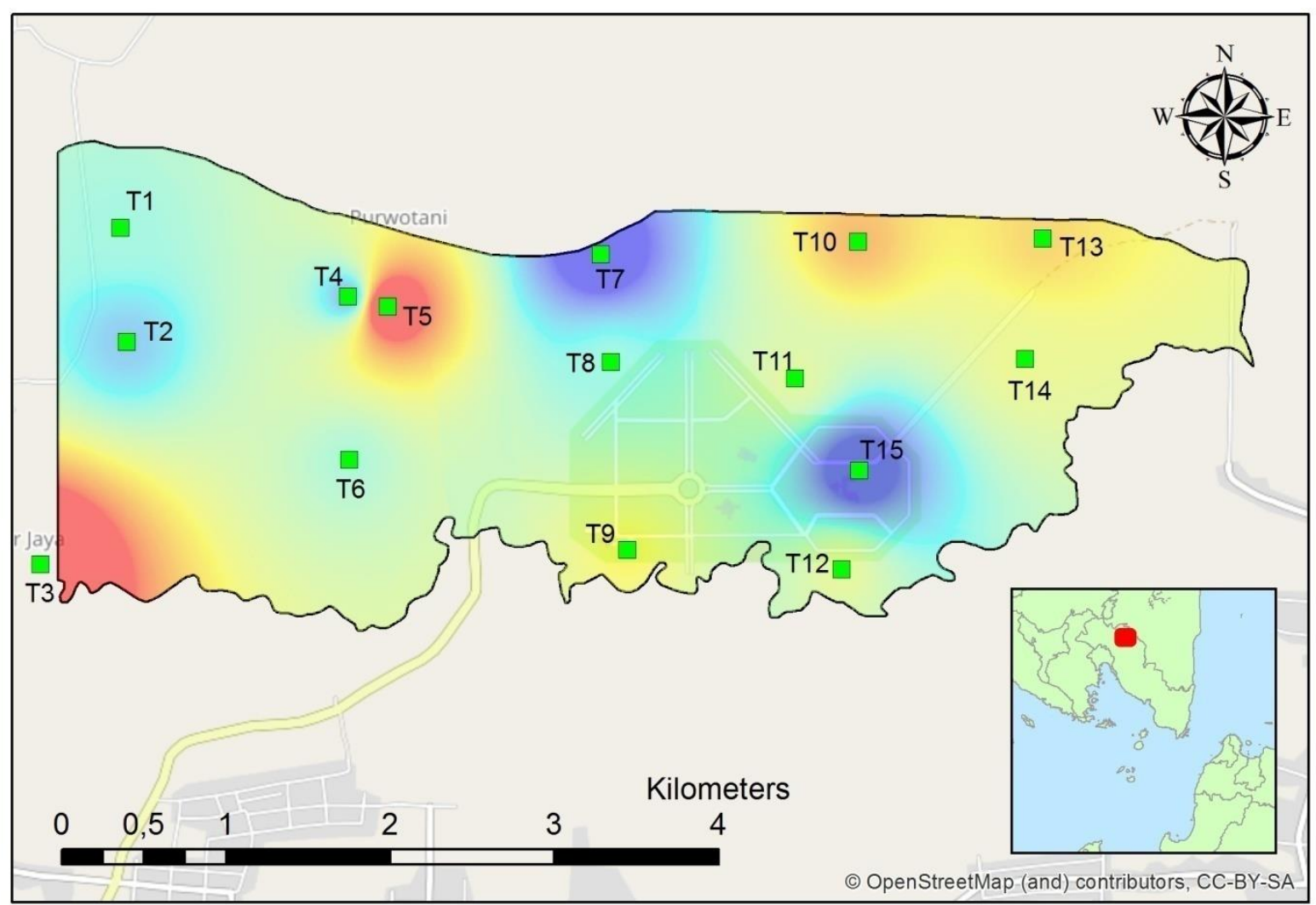

Figure 5. Kota Baru classification of seismic hazard map. The more red area means more hazardous because has higher value of $K_{g}$. The blue one can be interpreted as less hazardous area

\section{Acknowledgments}

This work was funded by Hibah Mandiri ITERA 2018

\section{References}

[1] SESAME European Research Project., 2004. Guidelines for the implementation of the H/V spectral ratio technique on ambient vibrations measurements, processing and interpretation.

[2] Okada, H., \& Suto, K. 2003. The Microtremor Survey Method. doi:10.1190/1.9781560801740

[3] Y Nakamura 1989 QR Railway Technical Research Institute 3025

[4] Y Nakamura 1996 Quarterly report of Railway Technical Research Inst. (RTRI) 37112 